\title{
Acolhendo as necessidades de saúde: um relato de experiência
}

\author{
Karolina Adrienne Silva Oliveira, Ariana Colombari de Godoi Floresta, Marianne Cabette de \\ Oliveira, Vanessa Santos de Souza, Paula de Vasconcelos Freira
}

\section{Resumo}

O atual cenário da saúde pública brasileiro prevê um modelo de assistência à saúde pautada na perspectiva da integralidade do cuidado, tendo a Atenção Básica como eixo estruturante do Sistema Único de Saúde (SUS). Nesta proposta de estruturação, pode-se destacar o acolhimento, diretriz integrante da Política Nacional de Humanização (PNH), que propõe a reorganização do processo de trabalho, pautando na necessidade do sujeito, a fim de garantir acesso universal, escuta qualificada e humanizada, viabilizando o primeiro contato do indivíduo com o serviço de saúde. A gestão do cuidado no município de Juiz de Fora, Minas Gerais passa a ser normatizado através do plano diretor da Atenção Primária à Saúde (PDAPS) a partir de 2014, e então o acolhimento é oficialmente implantado. Relatar a experiência do acolhimento em uma Unidade de Atenção Primária a Saúde (UAPS) de Juiz de Fora, Minas Gerais, sob a ótica de residentes em Saúde da Família do HU/UFJF. Trata-se de um estudo descritivo, relatando a experiência do acolhimento em uma UAPS de Juiz de Fora, Minas Gerais no período de abril a julho de 2016. O acolhimento acontece durante todo turno de trabalho, por profissionais de nível superior: Enfermeiro, Assistente Social e Dentista, incluindo residentes, com escalas de trabalho semanal. Ao chegarem, os usuários se organizam em fila e são direcionados às atividades da unidade: procedimentos, consultas ou demanda espontânea, denominada acolhimento. Os usuários inseridos no fluxo do acolhimento passam por escuta inicial, onde informam nome, número do cartão nacional de saúde, data de nascimento e queixa principal. Em seguida, de forma individualizada, este usuário é direcionado para sala, onde será realizado uma escuta qualificada, organizada e sistematizada, buscando responder as necessidades do usuário, seja por meio de consultas médicas, de enfermagem, odontologia, serviço social ou encaminhamentos para especialidades. Foi notória a importância do acolhimento para efetivação de vínculos com a comunidade, ampliação do acesso aos serviços, possibilitando maior integralidade entre as equipes e as categorias inscritas no serviço. Ainda, é possível perceber um avanço no que tange a compreensão dos usuários sobre a atuação dos profissionais da UAPS, visualizando a possibilidade de atendimento por uma equipe multidisciplinar, não centrado apenas na figura do profissional médico. A prática do acolhimento possibilita a criação de vínculo com usuário, o fortalecimento da comunicação entre a equipe e uma aprendizagem significativa frente às demandas diárias. Entretanto, vê-se a necessidade de inserir os demais profissionais da equipe no acolhimento, buscando o trabalho coletivo efetivo. Ainda é preciso pensar o acolhimento como uma realidade local, em processo de construção, sendo então necessário repensar fluxos e condutas, de modo a ofertar serviço de qualidade que atenda as reais necessidades da população e garanta acesso às políticas públicas.

Descritores: Acolhimento; Atenção Primária à Saúde; Humanização da Assistência. 